\title{
Rainforest conversion to rubber plantation may not result in lower soil diversity of bacteria, fungi, and nematodes
}

\begin{abstract}
Large areas of rainforest in Asia have been converted to plantations, with uncertain effects on soil biodiversity. Using standard metagenetic methods, we compared the soil biota of bacteria, fungi, and nematodes at three rainforest sites in Malaysia with two rubber plantation sites with similar soils and geology. We predicted the following: (1) that the rubber sites would have a lower $\alpha$ - and $\beta$-diversity than the rainforest sites, due to the monospecific canopy cover and intensive management with herbicides, pesticides, and fertilizers, and (2) that due to differences in the physical and biotic environment associated with cultivation, there would be distinct communities of bacteria, fungi, and nematodes. However, regarding (1), the results showed no consistent difference in $\alpha$ - and $\beta$-diversity of bacteria, fungi, or nematodes between rainforest and rubber plantation sites. It appears that conversion of rainforest to rubber plantations does not necessarily result in a decrease in diversity of soil biota. It may be that heterogeneity associated with the cultivation regimen compensates for loss of biotically imposed heterogeneity of the original rainforest. Regarding (2), as predicted there were statistically significant differences in community composition between rainforest and rubber plantation for bacteria, fungi, and nematodes. These differences could be related to a range of factors including light level, litter fall composition, $\mathrm{pH}, \mathrm{C}$ and $\mathrm{N}$, selecting a distinct set of soil taxa, and it is possible that this in itself would affect long-term soil function.
\end{abstract}

Keyword: Bacteria; Fungi; Metagenetic; Nematodes; Rainforest; Rubber plantation; Soil biota 